\title{
Sport coaches' experiences of athlete injury: The development and regulation of guilt
}

\author{
Martinelli, L. A. ${ }^{1}$, Day, M. C. ${ }^{2}$, Lowry, R. G ${ }^{2}$ \\ ${ }^{1}$ Kingston University \\ ${ }^{2}$ University of Chichester
}

Manuscript accepted for Publication in Sports Coaching Review

Abstract:

This study sought to examine coaches' stories of guilt in the specific context of athlete injury. Using narrative interviews with a diverse group of ten coaches, guilt was found to be a commonly experienced emotion that the participants also sought to regulate. The coaches' experiences of the embodiment and management of guilt is primarily, although not exclusively, interrogated using the mainstream psychological theorising of Kubany and Watson (2003). The article concludes by connecting the coaches' experiences of guilt with critiques of the prevailing deontological approach used to define what it means to be a 'good' sport coach. Here we suggest that dominant perspectives in coach education may be instrumental in entrenching coaches' experience of guilt.

Keywords: athletic injury, coaches, guilt, narrative, vicarious trauma 


\section{Introduction}

Research on the psychological consequences of athletic injury has predominantly focused on the perspectives and experiences of the injured athlete (e.g., Grindstaff, Wrisberg \& Ross, 2010; Walker, Thatcher, \& Lavallee, 2007; Wiese-Bjornstal, 2010). While the coach has been identified as an important member of an injured athlete's support network, there has been little consideration of the psychological ramifications that athlete injury may have for coaches (Bianco, 2001; Corbillon, Crossman, \& Jamieson, 2009; Robbins \& Rosenfeld, 2001). In an effort to address this discrepancy, Day, Bond, and Smith (2013) produced a narrative case study of two national level trampoline coaches, who were present during a training session in which one of their athletes sustained an open leg fracture. Their study demonstrated that even amongst coaches of the same sport who had witnessed the same injury, subsequent reactions and experiences could vary and converge. For example, while one coach attempted to downplay the severity, the other believed the injury posed a significant threat the athlete's physical integrity and athletic career. Despite these early differences, both coaches recalled episodes of involuntarily re-experiencing the event that were trigged upon re-entering the environment in which the incident had occurred and having contact with the injury athlete. Hence there was considerable effort exerted by the coaches to avoid conversations about the injury within the training environment. From these findings, Day et al. (2013) suggested a link exists between coaches' experiences of sporting injury and the symptoms of post-traumatic stress.

Post-traumatic stress is a popular conceptualisation of the way a person's subjective well-being, balance of affective states, and overall satisfaction and happiness may be compromised by an adverse event (Joseph \& Linley, 2005). Indeed, the oscillation between intrusions (e.g., re-experiencing) and avoidance of event-related 
stimuli after witnessing (i.e., vicarious exposure) or learning about (i.e., indirect exposure) an event involving actual or threatened serious injury, are recognised as part of a constellation of post-traumatic stress symptoms (Diagnostic and Statistical Manual of Mental Disorders, 2013; Friedman, 2013). In this regard, Day et al. (2013) highlighted how such avoidance was found to restrict coaches' abilities to receive social support, a strong predictor of the severity of, and recovery from, post-traumatic stress symptoms (Ozer, Best, Lipsey, \& Weiss, 2008).

For some readers, the proposition that sport injury may be conceptualised as a potentially traumatic event for coaches may be unconvincing, especially given that injury can be a regular and perhaps normalised part of working life as a sports coach (Frisch, Seil, Urhausen, Croisier, Lair, \& Theisen, 2009; Mattila, Parkkari, Koivusilta, Kannus, \& Rimpelä, 2009). However, in line with a schema-based theoretical perspective towards the development of post-traumatic stress (Janoff-Bulman, 1992; Joseph \& Linley, 2005; Park, 2010), an event may be psychologically traumatic because it has posed a meaningful threat to a person's individualised yet global beliefs and goals. For example, even where a coach appears knowledgeable of the risk of injury, its occurrence can be psychologically traumatic for two reasons. Firstly, it may deeply contradict existing understandings about why and how such injuries happen. Secondly, it can also impact upon individual self-perceptions in terms of the extent to which he or she believed themselves to be a good, moral, willing and/or capable coach. This suggests that the traumatic meaning of sport injury resides not in an objective assessment of severity and prevalence of an event, but in the coach's subjective appraisal of that event and the way in which it contradicts their expectations about the occurrence of injury and the self (Gabert-Quillen, Fallon, \& Delahanty, 2011). Simply put, the more the coach's initial appraisal of the event is discrepant with his or her pre- 
existing beliefs and goals connected to injury in sport, the greater the level of distress to the individual's subjective well-being will be.

Of recent debate within the mainstream psychological literature is the emotional content to psychological trauma. Older conceptualisation of a traumatic event (APA, 1994) required the individual to have experienced fear, helplessness or horror at the time of one's exposure to an event involving actual or threatened serious injury, in order to qualify as having been exposed to a traumatic event. Yet this peri-traumatic emotional configuration of fear, helplessness or horror has been removed from current conceptualisations of a traumatic event because of mounting evidence that posttraumatic symptoms could also develop if a person had experienced alternative peritraumatic emotions or even emotional numbing whilst in the process of witnessing or learning about such an event (Bovin \& Marx, 2001; Friedman, 2013; Hathaway, Boals, \& Banks, 2011). Moreover, in the most recent conceptualisation of post-traumatic stress offered by the DSM-5, a new symptom category was created to exclusively address negative alterations in mood and cognition. This indicated that a persistent negative emotional state which may involve fear, horror, anger, shame, or guilt could be experienced as part of one's response to experiencing, witnessing or learning about an event involving actual or threatened serious injury to qualify as having been exposed to a traumatic event.

Relative to the state of literature that conceptualises post-traumatic responses as a predominantly fear-based phenomenon, attention to trauma-related guilt is sparse. It is generally agreed that guilt is characteristically an intense and unpleasantly valenced affective state, accompanied by beliefs that one should have thought, felt or acted differently (Blum, 2008; Pugh, Taylor \& Berry, 2015). Thus, guilt constitutes a sense of wrongdoing because of the perceived connection between one's actions or inactions and 
a negative outcome. Although the experience of guilt following trauma has been a point of some theoretical and empirical interest, there is no conceptual consensus on this topic. For example, Lee, Scragg and Turner (2001) argued that guilt may be a disabling emotional response to a trauma event because it signals that the self is being experienced in a negative way. Blum (2008) meanwhile portrays guilt as a maladaptive emotion underpinning psychopathologies. Conversely, others address the more adaptive qualities of this emotion. In this regard, Baumeister, Stillwell, and Heatherton (1994) argued that guilt is a social emotion that serves to strengthen relationships by reducing the frequency of transgressions against others. Similarly, Carnì, Petrocchi, Del Miglio, Mancini and Couyoumdjian (2013) described guilt as a moral emotion that helps individuals adjust to, and adopt, cultural norms for the purpose of social survival. There is also a lack of consensus over the precise relationship between guilt and the development of post-traumatic stress. Here, whereas the DSM-5 (APA, 2013) situates guilt as one of a constellation of post-traumatic stress symptoms, Lee et al. (2001) and Kubany and Watson (2003) have forwarded models of trauma-related guilt that conceptualize the emotion as constitutive of a type of post-traumatic response that drives other symptoms of post-traumatic stress (Browne, Trim, Myers, \& Norman, 2015).

Given the different trajectories that guilt might have, and the lack of research undertaken to understand this emotion in the working lives of coaches, we explored coaches' experience of guilt in the specific context of athletic injury. As such, the current study provides an initial qualitative insight into the multifaceted development and regulation of guilt among coaches. In doing so, it illustrates the different ways that guilt may be embodied and subsequently managed by coaches in response to athletic injury. Such knowledge holds the potential to make an important contribution to the 
literature concerning trauma-related guilt and the emotional landscape of sport coaching more generally (Potrac et al., 2013).

\section{Methods}

\section{Participants and Sampling}

Ten sports coaches ( 6 male, 4 female) aged between 19-69 years were recruited. The participants had between 4 and 33 years coaching experience in the following sports: rugby $(n=2)$, football $(n=3)$, hockey $(n=2)$, basketball $(n=1)$, equestrian dressage $(n=1)$ and skiing $(n=1)$. All but one of the participants had obtained either a level one, two or three coaching qualification in the United Kingdom and coached in a variety of grassroots, recreational, and high performance settings. To facilitate the recruitment of coaches with a variety of experiences of sport injury, three sampling criteria were used. The criteria were informed by the definitions of a reportable sports injury recommended by the surveillance literature (Wiese-Bjornstal, 2010) and required the coaches to clarify if they had witnessed an injury that: (i) occurred during an organised session of training or competition, (ii) required immediate medical attention, and (iii) prevented the injured individual from resuming their participation in the organised session of training or competition. It is important to note that the injury criteria detailed above is indicative of an inclusive and subjective approach towards injury severity that reflected the coaches' sense making regarding severity of injuries (Bianco, 2001). This study received formal approval from the institutional ethics committee.

\section{Interviews}

Each coach participated in two semi-structured interviews that were conducted by the lead author. The semi-structured interview method entails the use of flexible, open- 
ended questions to explore the participants' thoughts, feelings and experiences (Sparkes $\&$ Smith, 2014). Following the completion of initial pilot work, the interview guide addressed the following topics: a) entrance into coaching, b) perspectives towards injury, c) contextual details surrounding the injury event, d) immediate responses to the injury, e) long-term responses to the injury, and f) further evaluations of the experience. In drawing upon narrative methodology, open-ended questions were utilised in order to encourage the interviewee to produce chronological accounts of their experiences (Smith \& Sparkes, 2009). Indeed, distinguishing narrative approaches from other modes of qualitative inquiry is its attention to the forging of temporal connections between the different events in the generation of meaning (Elliot, 2005; Squire, 2008; Polkinghorne, 1991, 1995). Furthermore, in accordance with schema-based theory (e.g., Day, 2012; Joseph \& Linley, 2005), some questions also sought to explore the interviewee's beliefs and goals connected to injury in sport and the extent to which these were discrepant with or changed by an particular experience of an athlete's injury.

The first interviews lasted between 64-241 minutes, and the second interviews lasted between 32-189 minutes. The decision to cease the interviewing process in this study was also informed by on-going discussions between myself, the principal researcher, and a senior colleague, who acted as a "critical-friend" (Sparkes \& Smith, 2014, p. 182). In these conversations I was encouraged me to critically reflect on the quality of the developing data in relation to the research aims, as well as my ability to cope with the data. The latter of which could be termed "researcher-saturation".

\section{Data Analysis}

The transcribed audio recordings of the interviews were analysed in a manner consistent with a holistic-content approach outlined by Lieblich, Tuval-Mashiach, and Zilber (1998). The advantage of taking a narrative and holistic approach to the analysis is that 
it avoids an excessive dissection of the interview transcripts that would otherwise result in decontextualized reading of the data (Riessman, 2008). The initial phase of analysis entailed engaging in empathetic readings of the data and documenting initial and global impressions. Here, for example, it was noted here that there was a tendency amongst the coaches to more comfortably elaborate on their evaluations of others' responses to a given sport injury rather than their own. Equally, moments of emotionality within the participants' stories of injury were typically short-lived and tended to interspace more analytical and procedural reflections pertaining to the incident. Within these moments of introspection, the coaches the experience of guilt was highlighted as a prominent emotion being spoken about or inferred to, and therefore became the "special foci of content or themes" for further analysis (Lieblich et al., 1998, p. 63). The final two steps of the analysis involved coding and tracking the development of this theme throughout the data set (Lieblich et al., 1998). Relevant extracts were then examined and clustered. From this point onwards, writing was employed as a method of analysis to develop and refine interpretations of composite themes (Richardson \& St. Pierre, 2005). Furthermore, throughout this process of analysis-by-writing, existing literature was regularly engaged with to make further sense of the data and to organise interpretations. In doing so, novel understandings are put forward whilst efforts are also made to connect coaches' responses to injury with mainstream theoretical propositions regarding the development and management of guilt following adverse events (Tracy, 2013).

\section{Judging this Study}

The current study was informed by an interpretivist philosophy, with research regarded as a shared and interactive process between the researcher and participant(s), who come together to create local meanings and knowledge (Denzin \& Lincoln, 2008; Lincoln, Lynham, \& Guba, 2011; Willing, 2008). The current study was also informed by a 
narrative methodology. In line with Smith and Sparkes (2009), a narrative approach to research is based on several principles, the first of which contends that a fundamental condition of being human is our propensity to actively construe meaning out of life's events and happenings. Indeed, as a species we are characterised by our endeavour to make sense of and thus give meaning to otherwise random, unrelated and inconsequential experiences. Narrative methodology therefore argues that meaning is not something that inherently resides in the events and happenings; rather it is something a person interprets and continually revises over time (Smith \& Sparkes, 2009). A second principle advocated by narrative methodology is the contention that meaning is achieved by humans through the use of narratives and in the act of storytelling (Andrews, 2000). Humans are characterised by an aptitude for narrative and to tell stories (Kramp, 2004), and it is through our engagement with narratives and storytelling that we make sense of our lives.

In reflecting the interpretivist philosophy underpinning this work, the reader is invited to judge the quality of this study in relation to the following non-foundational criteria (Smith, Sparkes \& Caddick, 2014).

- Do the data extracts provide a new or different understanding of the emotional experiences of coaches in the context of athletic injury?

- Is appropriate literature used in ways that helps to further unpack and explore the possible meanings of the coaches' experiences?

- How well are multiple realities and storylines negotiated?

\section{Results and Discussion}

Most prominent to the emotional landscape of the coaches' stories of sporting injury was the issue of guilt. This finding is unpacked and explored in relation to a) the 
development of guilt and b) the regulation of guilt. Participants and the individuals portrayed in their stories have been given pseudonyms.

\section{The Development of Guilt}

For many participants, guilt was an inevitable emotion after witnessing injury as a coach. For example, Lisa demonstrated this when recounting an injury that occurred during her first paid coaching session as an equestrian coach. In her own words:

... I did think at that point he'd broken his arm...yeah that was quite a traumatic experience and I always remember that that first one, there'll have been hundreds since then but I always remember that first one... It, it's almost like, um, a, I don't know how it is in other sports but for, certainly in equestrian, I always feel guilty if one of my riders have got, has got hurt. ...you're responsible for the safety of the people that you're coaching and that responsibility is really hammered into you and that guilt can be quite horrible afterwards... ...there's no difference to your realisation of what can happen, it's almost, it slams you the, pretty much in the gut sometimes, is that actually that was, whatever happens in that arena is your responsibility, so it's that, even if it's not your fault, it's your responsibility...

Lisa used the word 'traumatic' to describe that her response was infused with guilt. Interestingly, in stating that she 'always' felt guilt whenever her riders sustained injuries, Lisa suggested that there was an inevitable and perhaps customary level of guilt after an injury. Lisa perceived that guilt was not necessarily a consequence of a recognisable coaching action that had caused the injury ("even if it's not your fault"). Instead, her guilt stemmed from her position within a hierarchy of responsibility that compelled her to feel accountable for the safety of the individuals in her charge. This outlook reflected the work of Kubany and Manke (1995), who argued that the probability of experiencing trauma-related guilt is heightened by one's social position being confused as having the capacity and power to control all outcomes. 
While Lisa described immediate guilt, Andrew explained that his guilt was a product of post-event reflection. In his own words:

whether the coach is responsible or not, he [sic] is a definite part of any of injury because it is most likely that he would have been there when his athlete got injured and he will have had thoughts or feelings somewhere down the line (pauses) about guilt. I don't mean that he's guilty but as a coach he will be thinking 'could I have done this, could I have done that' and we can always look on, you know with hindsight; it's a wonderful thing...

According to Andrew, it is the coach's natural reflection in the aftermath of the incident that explains why guilt is an inevitable experience. Through the use of imaginary scenarios, Andrew considered courses of action different to those that were taken and which might have had a positive impact upon the extent or likelihood of the injury sustained. According to Kubany and Watson (2003) such cognitive activity is conducive to guilt, as it generates beliefs about the foreseeability and preventability of a negative event. Importantly, Kubany and Watson (2003) warned that such beliefs may be informed by hindsight bias (knowledge of the outcome), thereby increasing the magnitude of the guilt experienced. This knowledge of the outcome can prompt imaginary alternative actions to be perceived as options that were actually available to the coach. Andrew's comments therefore alert us that guilt may result from a coach's post-injury reflections, particularly if the coach is not able to distinguish between preevent and post-event knowledge. Coaches are increasingly encouraged to be reflective (Knowles, Borrie, \& Telfer, 2005), yet the emotional repercussions of the reflective process and the possibility of hindsight bias have not been acknowledged. From our perspective, this represents an important line of inquiry for scholars in the sports coaching community. 
Patrick, a 26-year-old football coach, offered an alternative account of guilt. For Patrick, guilt was immediate but cultivated through multiple interrelated thoughts about an injury. He stated:

“...the ground was hard...the surface was tricky, wasn't dangerous but it was tricky... ... she [player] tried turning away from the collision I believe and either got her feet stuck in the ground or her kind of her body turned too quickly for her legs......I just felt guilt from, from the first minute,...it was just the guilt......it wasn't too much panic, it was more a case of this game perhaps shouldn't be playable...that was the initial thought that (pauses) should we have actually kept this game on today? ...that was what was a bit more painful for me because I had, I had an influence on the surface. So I'd spoken to the grounds man, the officials and as a committee as such we decided to keep the match]on... so that's why there's that added sense of personal responsibility..."

In permitting a competitive match to take place on a 'tricky' surface, a causal link was created between his actions and the occurrence of the injury because, for Patrick, the most obvious and proximal cause of the injury was the questionable surface. Adding to the magnitude of guilt experienced by this coach was his realisation that the pre-match discussions and subsequent decisions made about the pitch could have been better. Patrick concluded that he had decided about the safety of the pitch from the perspective of a player rather than from the perspective of a coach. He noted:

"Most incidents happen, there's nothing prior... as I say, perhaps prior to the incident, that could have been managed better but it wasn't... ...I looked at it [the pitch] as if, well, I'd play on it... because I would kind of thing, but would I play on it safely? I don't know. Looking back now it's like poor decision..."

Patrick regretted that he had appraised the safety of the pitch in accordance with his personal willingness as a player himself. Here his experience corresponds with a particular cognition said to contribute to the magnitude of trauma-related guilt. Specially, a perceived insufficient justification for actions taken (Lee et al., 2001; 
Kubany \& Watson, 2003). Thus, in believing that one's actions or inactions connected to a negative event are lacking sufficient rationale or logic, the risk of experiencing guilt increases. Kubany and Manke (1995) further proposed that perceived insufficient justification and thus guilt can be heightened when one focuses on the positive outcomes that might have taken place if an alternative action had been executed. As Patrick described:

\footnotetext{
"she was playing just like really well...she was literally leading the line, causing problems and then it just happened... ... it shouldn't have happened to a player like this who's twenty years old, who is a good player, going places..."
}

Thus, the injured player's good performance on the day and her potential to have a promising football career also contributed to Patrick's guilt. As such, the coach's understanding of the injured athlete's actual or potential sporting ability could be a factor that heightens or lessons guilt.

Patrick's experiences overlap with comments from Jerry, a rugby coach, who elaborated on the circumstances surrounding an injury that would be more likely to arouse an emotional response from him. He noted:

...the only other thing then which would be shocking is, is, is the player involved in terms of knowing their history, so if they've just returned from injury and you feel for them because it couldn't have been worse luck, or a player who's got a trial or a, wanting to go on to bigger and better things, them being set back, they'd be the only things then which would emotionally trigger a reaction for me...

Although Jerry did not explicitly talk about guilt as an emotion constitutive of his experience of sport injury, there was an important recognition from him that his knowledge of the injured athlete could certainly make the incident more or less emotionally potent. Similarly, Eleanor described how her negative perception of an 
injured individual had made for a seemingly emotionally insignificant experience of injury incident during a competitive match. More specifically, Eleanor had dismissed a player's injury symptoms that would eventually be confirmed as indicative of a punctured lung; hence it was some hours before the injured player received medical care. Eleanor noted:

...one of the most serious injuries we've ever had...now I didn't talk about him last week [laughs] and my reason for that is probably what I'm going to try and justify here on the kind of personality things. He was a player who moaned at every opportunity, and I mean that in terms of feeling like he was hard-done-by by life as a whole......he was nowhere near the level that he should have been and, and quite frankly, without sounding really like I'm treading on him, never will be bless him...

Eleanor's negative understanding of the player quashed the possibility of experiencing guilt. One's knowledge of the injured individual has been suggested as a pre-trauma factor that can have a meaningful influence on the way the incident is construed by the witness of a traumatic event (Lerias \& Byrne, 2003). Moreover, Kubany and Watson (2003) proposed that close physical and personal proximity with the injured individual should increase the probability trauma-related guilt. In line with such theorising, Eleanor's negative regard for the injured athlete inferred little personal proximity between herself and the injured athlete. Such a relationship arguably prevented Eleanor from experiencing guilt in response to an incident in which the welfare of the injured athlete was essentially neglected.

The contention that there is a positive relationship between the coach having a close physical and personal proximity with the injured athlete and the magnitude of guilt was, however, contradicted by two coaches' stories of injury. Jade, a hockey coach 
of an under twelve years old team at a community-based sports club, recounted an injury sustained by a child:

...Jonathon, he'my best defender... ..... boy [opposition player] hit the ball really really hard, and it was in the air...it would have been a great shot, but Jonathon was there and it hit him right in the knee... he was on the floor, he was crying and he's kind of like, I like Jonathon because he's like me as a player, I see myself in him...... at such a young age I was like this could like destroy him because he's such a good player...... g guess it was just bad timing of how he [Jonathon] ran to the player and you can't really influence... actually it was a good thing that Jonathon went towards that player with the ball... Jonathon definitely did the right thing in going towards him to get the ball...

The injured child in Jade's story was portrayed in a positive light and liked by Jade, yet this coach's story was entirely absent of explicit or implicit inferences of guilt. This may be because Jade regarded the child's actions leading to the injury as unrelated to her coaching. Yet, as previously established through Lisa's comments, a coach does not always need to recognise such a connection to experience guilt. In an alternative story of sport injury that also challenges Kubany and Watson's (2003) hypothesis that a positive relationship exists between a person's close physical and personal proximity with the injured individual and the probability trauma-related guilt, Lisa spoke of a former rider's spinal cord injury:

...you can even feel guilty about people that you coach who injure themselves when it's nothing to do with you. So it's not in your session, and it's not in your [yard], but because you've taught them and they go out and do something else, and then they get injured, there is a little creeping feeling of guilt...I have a, a lady that I taught for about four or five years, who um took her horse out hunting, fell off her horse out drag hunting over a tiny little fence, and fractured her spine, is in a wheelchair for the rest of her life now, and that happened about eight weeks ago maybe... ...the awful thing is she's no great friend...I've never been round her house... I hadn't coached her for about six weeks because she'd moved yards and she'd gone quite a long way away from us and she'd actually changed coach... 
Lisa's comments are particularly novel because they document the possibility of slowly developing guilt, even when detached from the athlete. This particular case may be explained in relation to the permanent and life changing injuries faced by this athlete.

As Lisa explained:

“...I still can’t help feeling it, even though rationally I know it's totally ridiculous and I know it's totally ridiculous but you still kind of feel 'oh if only I'd coached her a little bit better', would she have sat up straight, would she have actually ridden that jump a bit better, would she have um not fallen off..."

For Lisa, a sense of responsibility remained even when no longer coaching the athlete. Lisa saw herself as an inextricable part of her riders' good or bad performances through her recognition of the part that she had played in helping the rider to acquire or develop skills and techniques that may be later used to evade the injury. This is in agreement with Kubany and Manke (1995), who outlined that an exaggerated sense of personal responsibility for an event and/or its outcomes is one of several thinking errors that increase the person's aptitude to experience guilt. Lisa's story suggests a need amongst some coaches for guidance with respect to responsibility boundaries, further her account may also prompt debate about where responsibility lines should be drawn whilst considering the consequences for both athlete and coach welfare (Simon, 2013; Cassidy, Jones, \& Potrac, 2009).

\section{The Regulation of Guilt}

For those coaches who had identified guilt in the aftermath of a sport injury, there were differences in their efforts to regulate their thoughts and affective states. Salient to the stories offered by both Patrick and Lisa was their avoidance of the injured individual. Patrick, for example, conveyed a desire to keep a physical distance between himself and the injured individual. He described: 
I didn't even want to go to the hospital because I felt that much guilt. So if it was professional, I would have gone straight to the hospital...I would have been there straight away after the game to be with Ashley...I just couldn't go, with it being, it being a bit more personal, I felt I must get out of this...I didn't know Ashley's reaction to maybe (pauses) her opinion on the game being on/off, I didn't want to cause friction or confrontation...

Patrick's description echoes the findings of Day et al. (2013), who reported that coaches found it emotionally distressing to be in contact with the injured athlete. Such avoidance strategies have also been reported from the perspective of the athlete, with injured swimmers suggesting that their attempts to communicate with their coach left them feeling overlooked and pushed aside (Abgarov, Jeffery-Tosoni, Baker, \& FraserThomas, 2012). Patrick's comments however highlighted that a coach's absence can be because the injured individual's response is a source of guilt for the coach. This corroborates Kubany and Watson's (2003) multi-dimensional model of guilt in which avoidance signifies one's need for short-term respite from the emotion.

Failing to visit the injured individual could, however, be a problematic experience. Patrick indicated that in failing to visit the injured player in hospital, he was failing to act in accordance with what would have been a more professional response to these circumstances. Similarly, Lisa's inability to be in the physical presence of the rider who had sustained a spinal cord injury was problematic because it deeply contradicted her sense of self:

I can't quite face going to see her yet . I mean which is really odd because I am quite a stoical person you know, I'll, you know [laughs] shove guts back into horses that have been, that are damaged... ...I'm surprised at how woosie I'm being about going to see her really ... I would have thought I would have been fine with that and there's so many things that I am fine with but I think 'oh no I'll just put that off for another week' and I'll just put that off for another week..." 
By avoiding the injured individual, Lisa acted in an unfamiliar way. Both Lee et al. (2001) and Kubany and Watson (2003) regarded a departure from a valued way of acting as a determinant of guilt. By using avoidance, Patrick and Lisa made little progress in gaining respite from their experiences of guilt. Consequently both attempted to use a combination of avoidance and approach. Taking small steps to contact the injured player, Patrick inquired about the injured player via teammates, whilst also sending gifts:

...but I made phone calls, texts, consistently instead because I didn't want to completely obviously reject her... ...I can't remember if I spoke to her specifically the next day but it would have been to somebody at the hospital, one of the other players... ...I managed to get some training kit from her favourite football team [and] a card for everyone to sign...that's what I think I'd want. So yeah more than anything it was just to reiterate that yeah you're not forgotten..."

Making contact with the injured player via others and by sending gifts to the injured player was a safer mode of regulating guilt for Patrick in the short-term. Eventually on seeing the injured athlete Patrick sought her forgiveness:

...she is a bubbly character, she was laughing, joking about it and it obviously helped. ...I apologised to her she was obviously saying of course it's not your fault, it happens, and that kind of thing really. ... for me as a coach it was perfect to see her again and yeah yeah it massively helps to have someone like her, who dealt with it. Just laughing it off as such....and just reiterate 'no everything's good, I'm okay, it's happened and it happens...

Forgiveness from others is an important way in which guilt related thoughts may be more permanently reduced and even eliminated (Kubany \& Watson, 2003). Patrick's story highlights that the first meeting between an injured athlete and a coach experiencing guilt can be crucial to changing the coach's emotional landscape in the aftermath of an injury. 
Other accounts of regulating guilt involved different trajectories, with one coach encouraging an injured athlete to take legal action. Andrew was acting as the assistant coach at a training camp for elite disability skiers when an athlete (Claude) with an existing amputation to the right limb sustained several fractures to his left limb. Prior to the accident, Andrew had noticed that several of the slalom poles were not properly drilled into the piste and relayed this to the head coach who subsequently informed the skiers about the risk. In the following quotation, Andrew speaks of his need for reparation:

...I could see that, you know, Claude may not walk again. I mean you have to think about that because it's a broken leg. It was a bad break, right on his boot, three broken bones...it upset me that we should have avoided it, it was avoidable...I was a part of the decision so I was just as culpable as the head coach... what we did was wrong you can't change it. It happened and you can't change it but you can possibly make reparation somewhere, you can try and make it a bit easier... ...my reaction was to encourage Claude to sue me and the head coach. Claude said, 'no I can't', but I continued to encourage him to sue me for a year. It may sound odd to you, but for me, that was quite important...I was aware that it would be a problem for me if Claude did sue me because it would have been in the papers but I felt that it was the right thing to do and I needed Claude to know that...

Andrew encouraged his athlete to take legal action, which would have involved a claim of negligence being brought against him (James, 2013). The initiation of legal proceedings could have jeopardised Andrew's reputation and career as a sports coach. However, he perceived this to be the best way to make amends for his error and to address his feelings of guilt.

Interestingly, for other coaches, the threat of legal action was problematic, inciting fear rather than the alleviation of guilt. For example, Lara stated: 
hey have to look at liability and things as well, and don't get me wrong at all, like, because I was completely worried about it... ... it was scary like, like I said you think about the person who's injured and then it's kind of the after thought of, especially in that situation like oh my God, I'm in so much trouble for this, like what if someone tried to sue me...

This situation is perhaps unsurprising given the compensation culture said to currently exist within sport (James, 2013) and this is compounded by an inconsistency with which different courts apply the principles underpinning claims of negligence (Partington, 2014). As such, it is understandable that coaches would shy away from emotional disclosures through fear that the expression of guilt could be used as some form of evidence by others that the coach was indeed liable and negligent. Conversely, for coaches such as Andrew, the possibility of legal action was viewed as the most appropriate way in which he might compensate an athlete for an injury that was a consequence of the coach's perceived wrongdoing. Compensation in the context of traumatic events has been linked to the witnesses' attempts to restore a sense of justice where it has been previously contradicted by the occurrence of harm to a seemingly undeserving individual (Hafer \& Bègue, 2005). Moreover, the use of self-punishment has been recognised as a guilt-regulating strategy employed by the supposed transgressor when direct compensation to the injured individual is not possible. It is said to act as an unequivocal social signal of remorse and desire for reparation that serves to restore the transgressor's relationship with the harmed individual and increases the potential for forgiveness (Nelissen, 2012).

\section{Conclusions}

The current study sought to provide some initial insights into the multifaceted development and regulation of guilt in coaches. The results indicated that guilt may be 
embodied and managed in different ways. In some instances, guilt is an immediate visceral response upon seeing a sport injury, whereas on other occasions guilt may develop through the coach's reflection upon the incident. With regard to the latter, imaginary past scenarios may portray the coach's actions as foreseeably causal to the injury and insufficiently justified. Furthermore, in cases where the injured athlete was portrayed by the coach in a particularly positive or negative light, the potential for guilt could be heightened or quashed, respectively. However, this positive relationship between guilt and a coach's physical and/or personal proximity with the injured athlete did not hold across all circumstances. Furthermore, in attempting to regulate guilt, the coaches described how keeping their distance from the injured athlete could provide a transient respite from their experiences of guilt. However, the continued avoidance of the injured athlete was also understood as an increasingly guilt-provoking course of action in itself. As such, while making contact with the injured athlete could be a problematic encounter for the coach, it could, depending on the athlete's anticipated or actual response to injury, also be a guilt dissipating and healing experience. In a more contentious trajectory of regulating guilt, it was found that a coach could engage in reparative action such as requesting the injured athlete to make a legal claim of negligence against him or her.

The claim that coaches will inevitably experience and thus need to regulate guilt in the context of sport injury is intuitive when we consider the wider social context in which the process of sports coaching currently takes place. Hardman and Jones (2013) suggested that the moral and ethical worlds of sports coaches are increasingly defined from a deontological perspective that centres on the coach's duties and their sports participants' entitlements, as evidenced in the development of generic standards of practice or codes of conduct. The standard duty of care is perhaps one of the most 
notable obligations of the coaching role in sport across all levels of competition, whereby the coach is required to exercise reasonable care to prevent reasonably foreseeable harm in light of the specific circumstances (James, 2013). As Sports Coach UK (2005) stated, individuals with good coaching practice are those who, "ensure that the environment is as safe as possible, taking into account and minimising possible risks" (p. 3). Importantly, McNamee (2011) insightfully critiques codes of practice that have come into being through the professionalization of sports coaching, stating that they “franchise 'blameability' [sic] and consequently 'punishability' [sic] to their respective organisations" (p. 25). Compounding this situation, is the "nebulous and woolly" nature of the standard duty of care that sports coaches are expected to champion. In practice, this fails to offer any articulation as to when the occurrence of an injury unequivocally does not infer a breach in the coach's obligated conduct (Partington, 2014, p. 236). Importantly, we may be left with situation where the mere presence of injury is seen to reflect a coach's failure to fulfil expectations and standards associated with his or her sporting role. This certainly represents an important avenue for future inquiry and on-going consideration.

\section{Acknowledgements}

Thank you to the participants who generously gave their time and personal stories.

\section{References}

Abgarov, A., Jeffery-Tosoni, S., Baker, J., \& Fraser-Thomas, J. (2012). Understanding social support throughout the injury process among interuniversity swimmers. Journal of Intercollegiate Sport, 5, 213-229.

American Psychiatric Association. (1994). Diagnostic and statistical manual of mental disorders $\left(4^{\text {th }}\right.$ ed.). Washington, DC: Author. 
American Psychiatric Association. (2013). Diagnostic and statistical manual of mental disorders ( $5^{\text {th }}$ ed.). Arlington, VA: Author.

Andrews, M. (2000). Introduction. In M. Andrews, S. D. Sclater, C. Squire, \& A. Treacher (Eds.), Lines of narrative: Psychosocial perspectives (pp. 77-80). London: Routledge.

Bianco, T. (2001). Social support and recovery from sport injury: Elite skiers share their experiences. Research Quarterly for Exercise and Sport, 72(4), 376-388.

Blum, A. (2008). Shame and guilt, misconceptions and controversies: A critical review of the literature. Traumatology: An International Journal, 14(3), 91-102.

Bovin, M. J., \& Marx, B. P. (2001). The importance of the peritraumatic experience in defining traumatic stress. Psychological Bulletin, 137(1), 47-67.

Bowen, G. A. (2008). Naturalistic inquiry and the saturation concept: A research note. Qualitative Research, 8(1), 137-152.

Browne, K. C., Trim, R. S., Myers, U. S., \& Norman, S. B. (2015). Trauma-related guilt: Conceptual development and relationship with posttraumatic stress and depressive symptoms. Journal of Traumatic Stress, 28(2), 134-141.

Carnì, S., Petrocchi, N., Del Miglio, C., Mancini, F., \& Couyoumdjian, A. (2013). Intrapsychic and interpersonal guilt: a critical review of the recent literature. Cognitive processing, 14(4), 333-346

Cassidy, T., Jones, R., Potrac, P. (2009). Understanding sports coaching. The social, cultural, and pedagogical foundations of coaching practice $\left(2^{\text {nd }}\right.$ ed.). Abingdon: Routledge.

Chase, S. E. (2005). Narrative inquiry: Multiple lenses, approaches, voices. In N. K. Denzin, \& Y. S. Lincoln (Eds.), The SAGE handbook of qualitative research ( $^{\text {rd }}$ ed, pp. 651-679). London: Sage.

Corbillon, F., Crossman, J., \& Jamieson, J. (2009). Injured athletes' perceptions of the social support provided by their coaches and teammates during rehabilitation. Journal of Sport Behavior, 32(2), 93-107.

Day, M. C., (2012). Coping with Trauma in Sport. In J. Thatcher, M. Jones, \& D. Lavallee (Eds.), Coping and emotion in sport ( $2^{\text {nd }}$ ed., pp.62-78). London: Routledge.

Day, M., Bond, K., \& Smith, B. (2013). Holding it together: Coping with vicarious trauma in sport. Psychology of Sport and Exercise, 14(1), 1-11. 
Denzin, N. K., \& Lincoln, Y. S. (2008). Introduction: The discipline and practice of qualitative research. In N. K. Denzin, \& Y. S. Lincoln (Eds.), The landscape of qualitative research (pp. 1-43). London: Sage.

Francis, J. J., Johnston, M., Robertson, C., Glidewell, L., Entwistle, V., Eccles, M. P., \& Grimshaw, J. M. (2010). What is an adequate sample size? Operationalizing data saturation for theory-based interview studies. Psychology and Health, 25(10), $1229-1245$.

Friedman, M. J. (2013). Finalizing PTSD in DSM-5: Getting here from there and where to go next. Journal of Traumatic Stress, 26, 548-556.

Frisch, A., Croisier, J. L., Urhausen, A., Seil, R., \& Theisen, D. (2009). Injuries, risk factors and prevention initiatives in youth sport. British Medical Bulletin, 92(1), 95-121.

Gabert-Quillen, C. A., Fallon, W., \& Delahanty, D. L. (2011). PTSD after traumatic injury: An investigation of the impact of injury severity and peritraumatic moderators. Journal of Health Psychology, 16(4), 678-687.

Grindstaff, J. S., Wrisberg, C. A., \& Ross, J. R., (2010). Collegiate athletes' experience of the meaning of athletic injury: A phenomenological investigation. Perspectives in Public Health, 130, 127-135.

Guest, G., Bruce, A., \& Johnson, L. (2006). How Many Interviews Are Enough? An Experiment with Data Saturation and Variability. Field Methods, 18(1), 59-82.

Hafer, C. L., \& Begue, L. (2005). Experimental research on just-world theory: problems, developments, and future challenges. Psychological Bulletin, 131(1), 128-167.

Hardman, A., \& Jones, C. (2013). Philosophy for coaches. In R. L. Jones, \& K. Kingston (Eds.), An introduction to sports coaching: Connecting theory to practice (pp. 99-111). Abingdon: Routledge.

Hathaway, L. M., Boals, A., \& Banks, J. B. (2011). PTSD symptoms and dominant emotional response to a traumatic event: An examination of DSM-IV criterion A2. Anxiety, Stress, \& Coping, 23(1), 119-126.

James, M. (2013). Sports law ( $2^{\text {nd }}$ ed.). Basingstoke: Palgrave MacMillan. Janoff-Bulman, R. (1992). Shattered assumptions. Towards a new psychology of trauma. New York: The Free Press. 
Joseph, A., \& Linley, P. A. (2005). Positive adjustment to threatening events: An organismic valuing theory of growth through adversity. Review of General Psychology, 9(3), 262-280.

Knowles, Z., Borrie, A., \& Telfer, H. (2005). Towards the reflective sports coach: Issues of context, education and application. Ergonomics, 48(11-14), 1711-1720.

Kubany, E. S., \& Watson, S. B. (2012). Guilt: Elaboration of a multidimensional model. The Psychological Record, 53(1), 4.

Kubany, E. S., \& Manke, F. P. (1995). Cognitive therapy for trauma-related guilt: Conceptual bases and treatment outlines. Cognitive and Behavioral Practice, 2(1), 27-61.

Lee, D. A., Scragg, P., \& Turner, S. (2001). The role of shame and guilt in traumatic events: A clinical model of shame-based and guilt-based PTSD. British Journal of Medical Psychology, 74(4), 451-466.

Lerias, D., \& Byrne, M. K. (2003). Vicarious traumatization: Symptoms and predictors. Stress and Health, 19(3), 129-138.

Lieblich, A., Tuval-Mashiach, R., \& Zilber, T. (1998). Narrative research: Reading, analysis, and interpretation. London: Sage.

Lincoln, Y. S., Lynham S. A., \& Guba, E. G. (2011). Paradigmatic controversies, contradictions, and emerging confluences, revisited. In N. K. Denzin, \& Y. S. Lincoln (Eds.), The SAGE handbook of qualitative research $\left(4^{\text {th }}\right.$ ed., pp. $97-$ 128).

Mattila, V. M., Parkkari, J., Koivusilta, L., Kannus, P., \& Rimpelä, A. (2009). Participation in sports clubs is a strong predictor of injury hospitalization: a prospective cohort study. Scandinavian Journal of Medicine \& Science in Sports, 19(2), 267-273.

McNamee, M. (2011). Celebrating trust, virtues and rules in the ethical conduct of sports coaches. In A. R. Hardman, \& C. Jones (Eds.), The ethics of sports coaching (pp. 23-41). Abingdon: Routledge.

Nelissen, R. M. (2012). Guilt-induced self-punishment as a sign of remorse. Social Psychological and Personality Science, 3(2), 139-144.

Nelson, L., Potrac, P., \& Groom, R. (2014). Receiving video-based feedback in elite ice-hockey: A player's perspective. Sport, Education, and Society, 19(1), 19-40. 
Nicholl, J. P., Coleman, P., \& Williams, B. T. (1995). The epidemiology of sports and exercise related injury in the United Kingdom. British Journal of Sports Medicine, 29(4), 232-238.

Ozer, E. J., Best, S. R., Lipsey, T. L., \& Weiss, D. S. (2008). Predictors of Posttraumatic Stress Disorder and Symptoms in Adults: A Meta-Analysis. Psychological Trauma: Theory, Research, Practice, and Policy, S(1), 3-36.

Park, C. (2010). Making sense of the meaning literature: An integrated review of meaning making and its effects on adjustment to stressful life events. Psychological Bulletin, 136(2), 257-301.

Partington, N. (2014). Legal liability of coaches: a UK perspective. The International Sports Law Journal, 14(3-4), 232-241.

Pugh, L. R., Taylor, P. J., \& Berry, K. (2015). The role of guilt in the development of post-traumatic stress disorder: A systematic review. Journal of Affective Disorders, 182, 138-150.

Richardson, L., \& St. Pierre, E. A. (2005). Writing: A method of inquiry. In In N. K. Denzin, \& Y. S. Lincoln (Eds.), The SAGE handbook of qualitative research $\left(3^{\text {rd }}\right.$ ed, pp. 959-978). London: Sage.

Riessman, C. K. (2001). Analysis of personal narratives. In J. F. Gubrium, \& J. A. Holstein (Eds.), Handbook of interview research: Context and method (pp. 695707). London: Sage.

Robbins, J. E., \& Rosenfeld, L. B. (2001). Athletes' perceptions of social support provided by their head coach, assistant coach, and athletic trainer, pre-injury and during rehabilitation. Journal of Sports Behavior, 24(3), 277-297.

Simon, R. L., (2013) Coaching, compliance and the law. In R. L. Simon (ed.), The Ethics of coaching sports. Moral, social and legal issues (pp. 187-192). Boulder, Colorador: Westview Press.

Smith, B., \& Sparkes, A. C. (2009). Narrative Inquiry in sport and exercise psychology: What can it mean and why might we do it? Psychology of Sport and Exercise, $10,1-11$.

Smith, B., Sparkes, A.C., \& Caddick, N. (2014). Judging qualitative research. In L. Nelson, R. Groom \& P. Potrac (eds), Research methods in sports coaching (pp. 192-202). London: Routledge

Sparkes, A. C., \& Smith, B. (2014). Qualitative research methods in sport, exercise and health: From process to product. London: Routledge. 
Sports Coach UK. (2005). Codes of practice for sports coaches. Leeds: The National Coaching Foundation.

Walker, N., Thatcher, J., \& Lavallee, D. (2007). Psychological responses to injury in competitive sport: A critical review. The Journal of The Royal Society for the Promotion of Health, 127(4), 174-180

Wiese-Bjornstal, D. M. (2010). Psychology and socioculture affect injury risk, response, and recovery in high-intensity athletes: A consensus statement. Scandinavian Journal of Medicine \& Science in Sport, 20(S2), 103-111.

Willig, C. (2008). Introducing qualitative research in psychology. Adventures in theory and method. Buckingham, Open University Press. 